\title{
The Psychologist:
}

Practice \& Research Journal

\section{Cognitive Performance in Non-Psychotic Non-Su- icidal Unipolar Depressed Patients}

\author{
Marco Moniz ${ }^{1,2,3}$ \\ ${ }^{1}$ Department of Psychiatry and Mental Health, Hospital and University Center of \\ Algarve, Faro, Portugal. \\ ${ }^{2}$ Research Centre for Spatial and Organizational Dynamics (CIEO), Faro, Portugal. \\ ${ }^{3}$ Algarve Biomedical Center $(A B C)$, Faro, Portugal
}

Corresponding author: Marco Moniz | emmoniz@gmail.com
Received:

08 October 2017

Accepted:

05 Junho 2018

\begin{abstract}
Background: Cognitive impairment is central in depression and executive dysfunctions in patients with depression are frequent. However, little attention has been paid to the specificities of executive changes in patients with unipolar depression, though these modifications may have serious implications for psychosocial functions and treatment of these patients.

Goals: To compare neuropsychological performance, regarding executive functions, of two adult groups: non-psychotic non-suicide attempters with unipolar depression and healthy individuals.

Methods: This is a cross-sectional study with data collected in an outpatient clinic of mental health service of a general hospital. We compared a group of non-psychotic non-suicidal unipolar depressed patients to a group of individuals without depression. Depressed subjects were controlled for prior suicidal attempts, and their neuropsychological profile was assessed using a range of measures of attention, verbal fluency, memory, psychomotor speed, and executive functioning (planning, decision making, set shifting, response inhibition, and inhibitory control).

Results: The group with depression $(n=23)$ was significantly outperformed by the group of healthy individuals $(n=23)$ in all measures. Also, differences in the executive functions of planning, decision making, set shifting, and inhibitory control were confirmed. We were unable to identify differences between non-suicidal individuals with depression and individuals without depression in terms of response inhibition, as has been the case in previous studies with samples with suicidal unipolar depressive patients.

Discussion: These results reinforce the hypothesis that there are specific alterations in patients with depression and highlight the need to develop specific cognitive rehabilitation programs for this population.
\end{abstract}

Keywords: Unipolar depression, Executive dysfunction, Attention, Verbal fluency, Psychomotor speed.

\section{Introduction}

Cognitive impairment has several impacts on the psychosocial functions of depressed patients, with cognitive dysfunction being a primary mediator of functional impairment in major depression (Lam, Kennedy, McIntyre, \& Khullar, 2014). Currently, we know the importance of cognitive dysfunction in depressed patients, the importance of their assessment for better rehabilitation, and the negative impact of antidepressant treatment on cognitive performance (Roca, Vives, Lopez-Navarro, Garcia-Campayo, \& Gili, 2015). Although cognitive dysfunction is a subject of extreme importance for the understanding of depression, we find few references to this point in nosological systems, particularly in DSM-V (APA, 
2013), which does not even refer to cognitive dysfunctions as criteria for major depression.

In a critical review, Roca et al. (2015) assessed the systematic reviews and meta-analysis studies published between 2004 and 2014, and identified a strong association between depression and cognitive impairment, particularly in psychomotor speed, attention, visual learning, memory, and executive functions. Although executive functioning is a central point in depression, particularly in unipolar depression (Rogers et al., 2004; Stordal et al., 2004; Wagner, Doering, Helmreich, Lieb, \& Tadić, 2012), there is lack of knowledge about which type of executive functions are affected with depression. Previous studies indicate differences between unipolar depressed patients and healthy individuals in set shifting (assessed with the Wisconsin Card Sorting Test) (Degl'Innocenti, Agren, \& Bäckman, 1998; Harvey et al., 2004; Moniz et al., 2016a; Moritz et al., 2002; Stordal et al., 2004), planning (assessed with the Tower of London) (Beats, Sahakian, \& Levy, 1996; Elliott et al., 1996; Moniz et al., 2016b; Rogers et al., 2004; Wagner et al., 2012), decision making (assessed with the lowa Gambling Task) (Cella, Dymond, \& Cooper, 2010; Moniz, Neves de Jesus, Gonçalves, Pacheco, \& Viseu, 2016c), and inhibitory control (assessed by Stroop tasks) (Gohier et al., 2009; Harvey et al., 2004; Moniz et al., 2016d; Stordal et al., 2004).

By considering the possibility of specific changes of executive functions among subjects with depression, the present study aims to compare neuropsychological performance, regarding executive functions, of two adult groups: non-psychotic non-suicide attempters with unipolar depression and healthy individuals. In light of previous studies, we hypothesize the following: (1) individuals with depression will perform more poorly than mentally healthy individuals on attention, verbal fluency, memory and psychomotor speed; (2) subjects with depression will generally exhibit more executive deficits than healthy individuals; and (3) subjects with depression and healthy individuals will not show differences regarding response inhibition.

\section{Methods}

This study followed a cross-sectional design, with data collected in an outpatient clinic of a mental health service of the Hospital and University Center of Algarve, according to a sequential sampling.

\section{Participants}

All subjects completed a battery of tests within one week (two different sessions). Each test was administered only once, and the order of presentation of cognitive tests was randomized for each of the subjects. All participants were Caucasian, right-handed, and Portuguese speakers. We circumscribe our clinical sample to non-psychotic non-suicide attempters with unipolar depression because the cognitive functions of bipolar subjects are believed to be influenced in a distinctive way (Stordal et al., 2004) and because suicide attempters with unipolar depression tend to reveal distinct cognitive functioning in response inhibition and planning (Moniz et al. 2017). Likewise, psychotic patients tend to exhibit more serious deficits (Stordal et al., 2004).

The exclusion criteria were: current or prior suicide attempts, bipolar disorder, schizophrenia, major psychosis, substance abuse, personality disorder, dementia, other neurological disease (including head injury involving a loss of consciousness), and suspected malingering.

\section{Instruments}

We conducted a detailed neuropsychological assessment, with computerized and standard paper-andpencil instruments that included: tests of attention, verbal fluency, memory, psychomotor speed, and executive functioning (planning, decision making, set shifting, response inhibition, and inhibitory control). To assess education, we calculated the number of years of formal education for each participant. We employed the following computer-administered instruments from the Psychology Experiment Building Language (PEBL) Test Battery (Mueller \& Piper, 2014):

Go/No-Go Task (GNG)

The GNG, in which a motor response must be either executed or inhibited, is one of the most useful 
measures for assessing response inhibition (Bezdjian, Baker, Lozano, \& Raine, 2009). We applied the "simple" paradigm in which the no-go stimulus was always the same. We used the Portuguese version (Moniz et al., 2016e) of the computerized GNG from the PEBL (Mueller \& Piper, 2014), developed and validated previously by Bezdjian, Baker, Lozano, and Raine (2009). The GNG demonstrates reasonable test-retest reliability (Kindlon, Mezzacappa, \& Earls, 1995).

\section{Victoria Stroop Test (VST)}

Inhibitory control is an important cognitive function associated with executive functioning and is assessed with tasks such as Stroop (Miyake et al, 2000). Our study employed the Portuguese version (Moniz et al., 2016d) of the computerized VST from the PEBL (Mueller \& Piper, 2014), a version that is briefer and slightly different from the traditional VST. The original version of the VST (Troyer, Leach, \& Strauss, 2006) demonstrated adequate psychometric data, namely regarding reliability and validity (Strauss, Sherman, \& Spreen, 2006).

\section{Tower of London Task (TOL)}

Inspired by the Tower of Hanoi, a classic problem-solving puzzle (Kaller, Unterrainer, Rahm, \& Halsband, 2004; McKinlay \& McLellan, 2011; Newman, Greco, \& Lee, 2009), the TOL is a visuospatial planning task (Kaller et al., 2004; McKinlay \& McLellan, 2011; Newman et al., 2009). We used the Portuguese version (Moniz et al., 2016b) of the computerized TOL from the PEBL (Mueller \& Piper, 2014), which does not differ from the manual versions in terms of the level of difficulty (McKinlay \& McLellan, 2011). Its reliability and validity were demonstrated by Piper et al. (2015), with a test-retest correlation coefficient of $r=.36$.

\section{lowa Gambling Task (IGT)}

The IGT aims to simulate real-life judgment alterations, allowing the assessment of the subject's emotions associated with decision making (Bechara, Damasio, Damasio, \& Anderson, 1994). The participants were instructed to perform a series of 100 selections from a group of four decks of cards (A, B, C and D). We used the Portuguese version (Moniz, Neves de Jesus, Gonçalves, Pacheco, \& Viseu, 2016c) of the computerized IGT from the PEBL (Mueller \&
Piper, 2014). Its reliability and validity were demonstrated by Piper et al. (2015), with a test-retest correlation coefficient of $r=.41$.

\section{Wisconsin Card Sorting Test (WCST)}

The WCST is one of the most frequently used neuropsychological measures for assessing executive functioning, and is commonly utilized to assess set maintenance and set shifting (Carrillo-de-la-Peña \& García-Larrea, 2007). The participants are expected to place cards in one of four piles according to the characteristics of the stimuli. We utilized a total number of 128 cards (i.e., two packs of 64 cards) and the principles were color, form or number, which changed every ten trials. After each trial, feedback ("correct" or "incorrect") was displayed for 500 milliseconds. The results obtained for each trial were provided by the software. We applied the Portuguese version (Moniz et al., 2016a) of the computerized WCST from the PEBL (Mueller \& Piper, 2014). Its reliability and validity were demonstrated by Piper et al. (2015), with a testretest correlation coefficient of $r=.45$.

\section{Finger Tapping Task (FTT)}

The FTT assesses fine motor speed and motor control (Christianson \& Leathem, 2004). The Portuguese version (Moniz, De Jesus, Pacheco, Gonçalves, \& Viseu, 2016f) of the computerized FTT from the PEBL (Mueller \& Piper, 2014) was used, with the left and right index fingers: five consecutive trials for each hand, with a 10-second break following each trial and a 30-second break every five trials. The average number of taps over five trials was calculated for each hand. The reliability and validity of the computerized FTT were demonstrated by Hubel, Yund, Herron, and Woods (2013a, 2013b), with a test-retest correlation coefficient of $r=.88$.

For computerized tests, we used a computer that ran Microsoft Windows 8.1, equipped with a touch screen (IGT, TOL, WCST), a keyboard (VST), and an external keypad (for FTT and GNG).

The paper-and-pencil instruments that were used are:

\section{Trail Making Test (TMT)}

The TMT, which comprises two parts (trials A and B). Trial $A$ of the TMT assesses attention, visual scanning, and information processing (Cavaco et al., 2008a, 
2013a). Participants are given two sets of dots targeting numbers and are expected to connect them in sequential order (e.g., 1-2-3). Trial B assesses working memory and executive functions, such as the ability to switch between sets of stimuli (Cavaco et al., 2008a, 2013a). The B/A performance ratio provides an index of executive function (Arbuthnott \& Frank, 2000). For trial B, participants are given two sets of 25 dots, one corresponding to numbers (1-13) and the other corresponding to letters $(A-L)$ in sequential order. The sequence begins with the first number, followed by the first letter alphabetically, then the second number, and so on (e.g., 1-A-2-B-3). We used the Portuguese version (Cavaco et al., 2013a).

\section{Verbal Fluency Test (VFT)}

In addition to executive functions, the VFT measures non-motor processing speed and language production, which recruit the pre-frontal cortex and temporal lobes (Cavaco et al., 2013b). The VFT consists of two tasks, measuring semantic and phonemic fluency. Subjects are asked to name as many animals as possible in 60 seconds and to say as many words as possible beginning with $M, R$, and $P$, in 60 seconds (for each letter), as described in the norms of the Portuguese version (Cavaco et al., 2013b).

\section{Verbal Fluency Test (VFT)}

Considered a measure that is sensitive to verbal memory deficits and neurological impairment, the AVLT evaluates memory and verbal learning (Cavaco et al., 2008b) through five consecutive trials. After a 30-minute break, participants are expected to recall the words that included the original word from a longer list. We used the Portuguese version (Cavaco et al., 2008b).

\section{Procedures}

All participants were assessed by a psychologist who was specifically certified for this purpose. During the selection of the sample, depression diagnoses were confirmed using the MINI International Neuropsychiatric Interview (MINI) (Sheehan et al., 1997) and the
Portuguese version of the Brief Symptom Inventory (BSI) (Canavarro, 2007). Symptomatology of depression was evaluated using the 17-item Hamilton Depression Rating Scale (HAM-D-17) (Sousa, Lopes, \& Vieira, 1979). To screen for the presence of personality disorders, the PDQ-4 + Personality Diagnostic Questionnaire (Hyler, 1994) was applied.

\section{Data analysis}

All analyses were conducted using the Statistical Package for Social Sciences (SPSS), version 21.0. The level of significance was set at $p<.05$. The normality of the distribution for continuous variables was tested with the Shapiro-Wilk test. A chi-square test was used to compare the categorical variables, and a t-test was used to compare continuous variables.

\section{Ethical issues}

This study was approved by the Hospital and University Center of Algarve Ethics Committee and was conducted according to the principles of the Declaration of Helsinki. After being provided with all information about the study, participants signed an informed consent form. For ethical reasons, we could not assess the clinical sample without medication.

\section{Results}

\section{Group characteristics}

The group of patients with depression was composed of 15 women and 8 men, with a mean age of 47.30 years old $(S D=14.97)$ and a mean of $8.73(S D=2.70)$ years of education. The group of healthy individuals, with analogous characteristics, included 15 women and 8 men, with a mean age of 43.70 years $(S D=$ $11.89)$ and a mean of $9.70(S D=1.85)$ years of education. The group of patients with depression and the healthy individuals did not differ significantly regarding age ( $t=.905, d f=44, p=.370, d=.27)$ or education $(t=-1.527, d f=39.01, p=.135, d=-.45)$ (Table 1$)$. 
Table 1. Sociodemographic characteristics, clinical profile, and cognitive measures of participants

\begin{tabular}{|c|c|c|c|}
\hline & $\begin{array}{l}\text { Patients with } \\
\text { depression }^{\text {a }}\end{array}$ & $\begin{array}{c}\text { Individuals without } \\
\text { depression }\end{array}$ & $p$-value \\
\hline & $M(S D)$ & $M(S D)$ & \\
\hline \multicolumn{4}{|l|}{ Social and Clinical Measures } \\
\hline Age, Years & $47.30(14.97)$ & 43.70 (11.89) & .370 \\
\hline Education & $8.73(2.70)$ & $9.78(1.85)$ & .135 \\
\hline BSI-D, Score & $2.23(.92)$ & (a) & (a) \\
\hline HAM-D-17, Score & $17.13(6.97)$ & (a) & (a) \\
\hline \multicolumn{4}{|l|}{ Cognitive Measures } \\
\hline VFT-Semantic Fluency-Animals & $14.60(4.65)$ & (a) & (a) \\
\hline VFT-Phonemic Fluency-(M, R, P) & $22.13(7.62)$ & (a) & (a) \\
\hline AVLT-Immediate Recall & $47.17(9.67)$ & (a) & (a) \\
\hline AVLT-Delayed Recall (30') & $9.91(2.19)$ & (a) & (a) \\
\hline AVLT-Memory Retention & $85.24(9.39)$ & (a) & (a) \\
\hline TMT-Part A & 54.15 (16.69) & $35.12(14.16)$ & .001 \\
\hline TMT-Part B & $145.65(55.85)$ & $71.89(30.51)$ & .001 \\
\hline TMT-B/A & $2.74(1.0)$ & $2.10(.53)$ & .027 \\
\hline FTT-Dominant Hand & $52.86(7.55)$ & $62.43(7.32)$ & .000 \\
\hline FTT-Non-Dominant Hand & $46,04(7.30)$ & $53.21(6.48)$ & .001 \\
\hline TOL-Extra Moves & $24.90(10.55)$ & $15.34(7.06)$ & .001 \\
\hline TOL-Time & $443.30(193.47)$ & $268.14(59.53)$ & .000 \\
\hline IGT-Net Score & $5.94(22.35)$ & $30.38(23.49)$ & .002 \\
\hline WCST-CAT (Moves to Complete $1^{\text {st }}$ Category) & $23.95(22.25)$ & $14.61(4.89)$ & .067 \\
\hline WCST-PE (Preservative Errors) & $18.77(10.46)$ & $8.14(5.81)$ & .000 \\
\hline WCST-CLR (Conceptual-Level Responses) & $60.45(16.07)$ & $78.00(10.51)$ & .000 \\
\hline VST-Errors & $3.25(3.24)$ & $1.18(1.73)$ & .017 \\
\hline VST-C Time & $111.86(73.85)$ & $63.77(22.16)$ & .010 \\
\hline GNG-CE (Commission Errors) & $6.60(4.10)$ & $6.39(3.10)$ & .840 \\
\hline GNG-OE (Omission Errors) & $1.26(2.02)$ & $.21(.51)$ & .025 \\
\hline Reaction Time, ms (Go) & $560.37(93.65)$ & $504.89(80.94)$ & .037 \\
\hline Reaction Time, ms (No-Go) & $588.56(81.15)$ & $537.57(53.00)$ & .015 \\
\hline \multicolumn{4}{|c|}{$\begin{array}{l}{ }^{\mathrm{a}} n=23{ }^{\mathrm{b}} \mathrm{n}=23 ; \text { BSI-D: Depression scale from the Brief Symptom Inventory; HAM-D-17: Hamilton De- } \\
\text { pression Rating Scale, } 17 \text { items; VFT: Verbal Fluency Test; AVLT: Auditory Verbal Learning Test; TMT: } \\
\text { Trail Making Test; FTT: Finger Tapping Task; TOL: Tower of London; IOWA: Bechara (lowa) Gambling } \\
\text { Task; WCST: Wisconsin (Berg) Card Sorting Test } \\
\text { (a) these data were not collected }\end{array}$} \\
\hline
\end{tabular}

\section{Neuropsychological performance}

The patients with depression were significantly outperformed by the healthy individuals in almost all measures, with differences between the two groups for the TMT [part A $(t=3.719, d f=37, p=.001$, $d=1.23)$, part B $(t=4.796, d f=37, p \leq .001, d=1.53)$, and $\mathrm{B} / \mathrm{A}$ ratio $(t=2.310, d f=37, p=.027, d=.80)]$, for the FTT [dominant hand $(t=-4.357, d f=44, p \leq .001$, $d=1.28)$, and non-dominant hand ( $t=-3.522, d f=44$, $p=.001, d=1.04)$ ], for the TOL [extra moves $(t=3.588$, $d f=43, p=.001, d=1.06)$, time $(t=4.066, d f=24.78$, $p \leq .001, d=1.22)$ ], for the IGT-Net Score $(t=-3.361$, $d f=38, \mathrm{p}=.002, \mathrm{~d}=-1.06)$, for the WCST [moves $(t=1.919, d f=23.11, p=.067, d=.58)$, for preservative errors $(t=4.141, d f=33, p \leq .001, d=1.26)$, for the $\operatorname{CLR}(t=-4.213, d f=41, p=.000, d=-1.29)]$, and for the VST [errors $(t=2.541, d f=28.44, p=.017, d=$ $.80)$, time $(t=2.800, d f=22.10, p=.010, d=.88)]$.

In the GNG task, we found differences between the two groups with regard to commission errors ( $t=.203$, $d f=44, p=.840, d=.06$ ) and omission errors $(t=2.391, d f=24.86, p=.025, d=.71)$. However, the difference in commission errors was not significant $(p=.840)$.

For the VFT and AVLT, we did not assess healthy individuals; instead, we used Cavaco et al. (2008b, 2013b) as a reference. Analyzing the $z$ score in these two instruments, although inferior to the average of the Portuguese population, we obtained values below standard deviation -.2, particularly on the AVLT (Figure 1). 


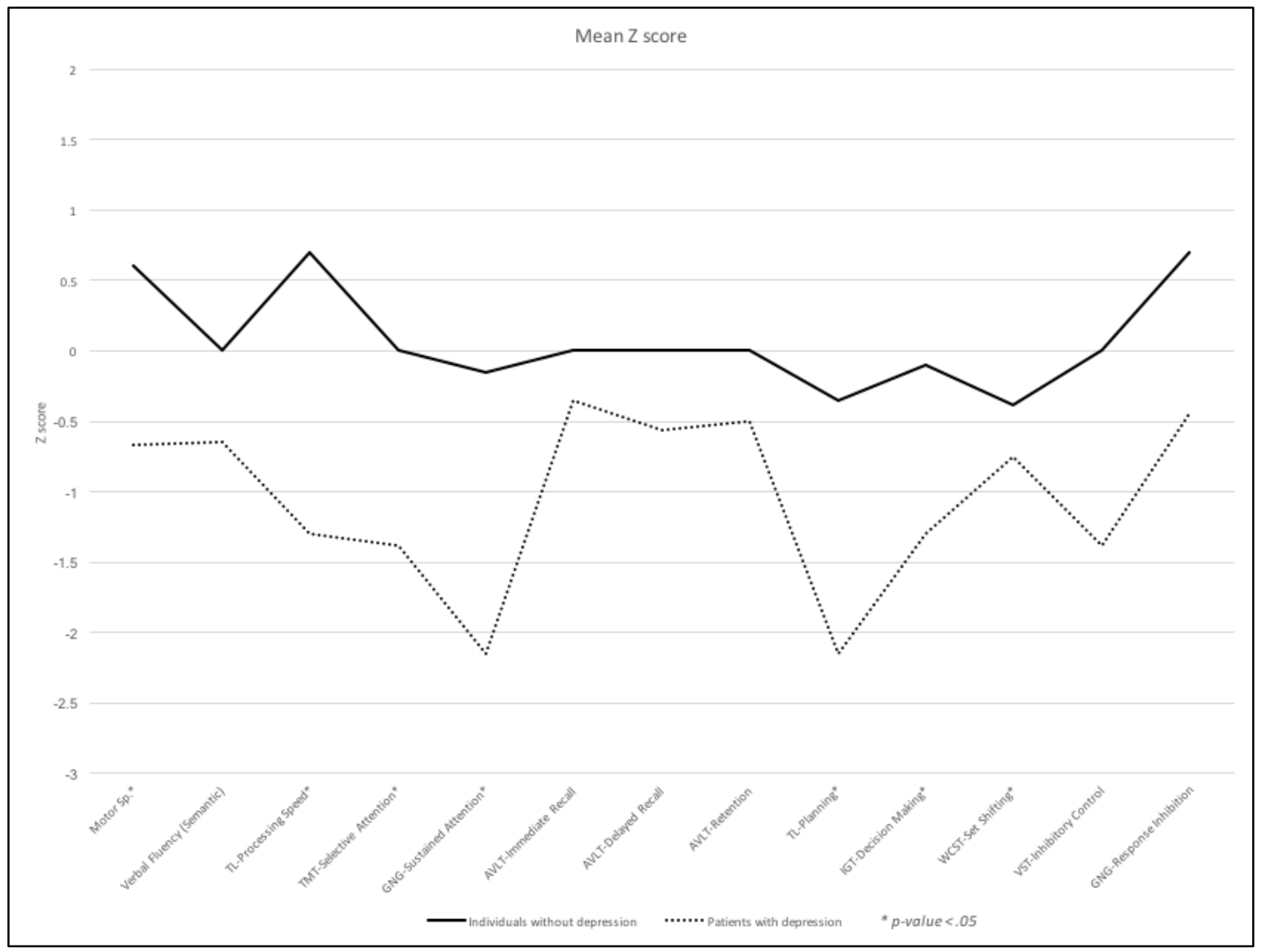

Figure 1. Z-scores of the neuropsychological tests (cognitive domains) by sample

\section{Discussion}

Our results are in line with studies that have revealed changes in attention, verbal fluency, memory and psychomotor speed (Bashir, Khade, Kosaraju, Kumar, \& Rani, 2013; Hueng et al., 2011; Kertzman et al., 2010; Lampe, Sitskoorn, \& Heeren, 2004; Moniz, De Jesus, Pacheco, Gonçalves, \& Viseu, 2016; Roca et al., 2015; Rohling, Green, Allen, \& Iverson, 2002), with the exception that in our study the differences in memory were not statistically significant. Therefore, our first hypothesis (i.e., that individuals with depression will perform more poorly than individuals without depression) was only partially confirmed.

Confirming our second hypothesis, the group of patients with depression were outperformed by the healthy individuals on most tests assessing executive functions, in line with studies that found changes in planning (Beats et al., 1996; Elliott et al., 1996; Moniz et al., 2016b; Rogers et al., 2004; Wagner et al., 2012), decision making (Cella et al., 2010; Moniz et al., 2016c), set shifting (Degl'Innocenti et al., 1998; Harvey et al., 2004; Moniz et al., 2016a; Moritz et al., 2002; Stordal et al., 2004), and inhibitory control (Gohier et al., 2009; Harvey et al., 2004; Moniz et al., 2016d; Stordal et al., 2004). Similar to what has been reported by Moniz et al. (2017), our group of patients with depression did not perform worse than healthy individuals in GNG commission errors. These finding confirms our third hypothesis (i.e., that individuals with depression and individuals without depression do not show differences regarding the performance of response inhibition).

\section{Conclusion}

The results of the present study confirm the association between executive functioning deficits and unipolar depression, particularly in the following executive functions: planning, decision making, set shifting, and inhibitory control. We also confirmed differences between patients with depression and 
healthy individuals in the performance of attention, verbal fluency and motor speed.

These results reinforce the need for clinicians and researchers to create a specific cognitive rehabilitation program for unipolar depression, taking into consideration cognitive changes inherent to this pathology. There are some existing cognitive rehabilitation programs for depression, but those programs target postinjury depression, which is considered a secondary and reactive clinical status, for example, of a stroke (e.g., Sohlberg \& Mateer, 2001). Therefore, these programs are not very specific and do not really target the specific cognitive implications of depression. Since cognitive changes are transient in depressed patients, a rehabilitation program have the potential to allow faster improvement in cognitive performance, symptoms of depression, and psychosocial functions, thus promoting a faster return to working life and reduced costs associated with this disease.

\section{Acknowledgements}

We thank all participants of this study.

\section{Declaration of Conflicting Interests}

The authors declare no conflicts of interest with respect to the research, authorship, and/or publication of this article.

\section{References}

American Psychiatric Association. (2013). Diagnostic and Statistical Manual of Mental Disorders (5th ed.). Washington, DC: American Psychiatric Publishing.

Arbuthnott, K., \& Frank, J. (2000). Trail Making Test, Part B as a Measure of Executive Control: Validation Using a SetSwitching Paradigm. Journal of Clinical and Experimental Neuropsychology, 22, 518-528. https://doi.org/10.1076/ 1380-3395(200008)22:4;1-0;FT518.

Bashir, M., Khade, A., Kosaraju, S., Kumar, C. V., \& Rani, U. (2013). Comparative Study of Psychomotor Performance in Depression Patients with Healthy Volunteers. Research and Reviews: A Journal of Medical Science and Technology, 2, 15-18.
Beats, B. C., Sahakian, B. J., \& Levy, R. (1996). Cognitive performance in tests sensitive to frontal lobe dysfunction in the elderly depressed. Psychological Medicine, 26, 591603. https://doi.org/10.1017/S0033291700035662

Bechara, A., Damasio, A. R., Damasio, H., \& Anderson, S. W. (1994). Insensitivity to future consequences following damage to human prefrontal cortex. Cognition, 50, 7-15. https://doi.org/10.1016/0010-0277(94)90018-3

Bezdjian, S., Baker, L. A., Lozano, D. I., \& Raine, A. (2009). Assessing inattention and impulsivity in children during the Go/NoGo task. British Journal of Developmental Psychology, 27, 365-383. https://doi.org/10.1348/ $026151008 \times 314919$

Canavarro, M. C. (2007). Inventário de sintomas psicopatológicos (BSI): Uma revisão crítica dos estudos realizados em Portugal. In M. R. Simões, C. Machado, M. M. Gonçalves, \& L. S. Almeida (Eds.), Avaliação psicológica: Instrumentos validados para a população portuguesa (pp. 305-330). Coimbra, Portugal: Quarteto Editora.

Carrillo-de-la-Peña, M. T., \& García-Larrea, L. (2007). Right frontal event related EEG coherence (ERCoh) differentiates good from bad performers of the Wisconsin Card Sorting Test (WCST). Neurophysiologie Clinique/Clinical Neurophysiology, 37, 63-75. https://doi.org/10.1016/ j.neucli.2007.02.002

Cavaco, S., Goncalves, A., Pinto, C., Almeida, E., Gomes, F., Moreira, I., ... Teixeira-Pinto, A. (2013a). Trail making test: Regression-based norms for the Portuguese population. Archives of Clinical Neuropsychology, 28, 189-198. https://doi.org/10.1093/arclin/acs115

Cavaco, S., Gonçalves, A., Pinto, C., Almeida, E., Gomes, F., Moreira, I., ... Teixeira-Pinto, A. (2013b). Semantic fluency and phonemic fluency: Regression-based norms for the Portuguese population. Archives of Clinical Neuropsychology, 28, 262-271. https://doi.org/10.1093/arclin/act001

Cavaco, S., Pinto, C., Gonçalves, A., Gomes, F., Pereira, A., \& Malaquias, C. (2008a). Trail making test: Dados normativos dos 21 aos 65 anos. Psychologica, 49, 222-238.

Cavaco, S., Pinto, C., Gonçalves, A., Gomes, F., Pereira, A., \& Malaquias, C. (2008b). Auditory verbal learning test: Dados normativos dos 21 aos 65 anos (norms for 21-65 years old). Psychologica, 49, 208-221.

Cella, M., Dymond, S., \& Cooper, A. (2010). Impaired flexible decision-making in major depressive disorder. Journal of Affective Disorders, 124, 207-210. https://doi.org/ 10.1016/j.jad.2009.11.013

Christianson, M. K., \& Leathem, J. M. (2004). Development and standardisation of the computerised finger tapping test: Comparison with other finger tapping instruments. New Zealand Journal of Psychology, 33, 44-49.

Degl'Innocenti, A, Agren, H., \& Bäckman, L. (1998). Executive deficits in major depression. Acta Psychiatrica Scandinavica, 97, 182-188. https://doi.org/10.1111/j.16000447.1998.tb09985.x

Elliott, R., Sahakian, B. J., McKay, A. P., Herrod, J. J., Robbins, T. W., \& Paykel, E. S. (1996). Neuropsychological impairments in unipolar depression: The influence of perceived failure on subsequent performance. Psychological Medicine, 26, 975-989. https://doi.org/10.1017/ S0033291700035303

Gohier, B., Ferracci, L., Surguladze, S. a, Lawrence, E., El Hage, W., Kefi, M. Z., ... Le Gall, D. (2009). Cognitive inhibition and working memory in unipolar depression. 
Journal of Affective Disorders, 116, 100-105. https://doi.org/10.1016/j.jad.2008.10.028

Harvey, P. O., Le Bastard, G., Pochon, J. B., Levy, R., Allilaire, J. F., Dubois, B., \& Fossati, P. (2004). Executive functions and updating of the contents of working memory in unipolar depression. Journal of Psychiatric Research, 38, 567-576. https://doi.org/10.1016/j.jpsychires.2004.03. 003

Hubel, K. A., Yund, E. W., Herron, T. J., \& Woods, D. L. (2013a). Computerized measures of finger tapping: Reliability, malingering and traumatic brain injury. Journal of Clinical and Experimental Neuropsychology, 35, 745-758. https://doi.org/10.1080/13803395.2013.824070

Hubel, K. A., Yund, E. W., Herron, T. J., \& Woods, D. L. (2013b). Computerized measures of finger tapping: Effects of hand dominance, age, and sex. Perceptual \& Motor Skills: Motor Skills \& Ergonomics, 116, 1-24.

Hueng, T.-T., Lee, I. H., Guog, Y.-J., Chen, K. C., Chen, S. S., Chuang, S. P., ... Yang, Y. K. (2011). Is a patient-administered depression rating scale valid for detecting cognitive deficits in patients with major depressive disorder? Psychiatry and Clinical Neurosciences, 65, 70-76. https://doi.org/10.1111/j.1440-1819.2010.02166.x

Hyler, S. E. (1994). Personality diagnostic questionnaire. New York, NY: New York State Psychiatric Institute.

Kaller, C. P., Unterrainer, J. M., Rahm, B., \& Halsband, U. (2004). The impact of problem structure on planning: Insights from the Tower of London task. Cognitive Brain Research, 20, 462-472. https://doi.org/10.1016/j.cogbrainres.2004.04.002

Kertzman, S., Reznik, I., Hornik-Lurie, T., Weizman, A., Kotler, M., \& Amital, D. (2010). Stroop performance in major depression: Selective attention impairment or psychomotor slowness? Journal of Affective Disorders, 122, 167-173. https://doi.org/10.1016/j.jad.2009.08.009

Kindlon, D., Mezzacappa, E., \& Earls, F. (1995). Psychometric properties of impulsivity measures: Temporal stability, validity and factor structure. Journal of Child Psychology and Psychiatry, 36, 645-661.

Lam, R. W., Kennedy, S. H., McIntyre, R. S., \& Khullar, A. (2014). Cognitive Dysfunction in Major Depressive Disorder: Effects on Psychosocial Functioning and Implications for Treatment. The Canadian Journal of Psychiatry, 59, 649-654. https://doi.org/10.1177/0706743714059012 06

Lampe, I. K., Sitskoorn, M. M., \& Heeren, T. J. (2004). Effects of recurrent major depressive disorder on behavior and cognitive function in female depressed patients. Psychiatry Research, 125, 73-79. https://doi.org/10.1016/ j.psychres.2003.12.004

McKinlay, A., \& McLellan, T. (2011). Does mode of presentation affect performance on the Tower of London task?. Clinical Psychologist, 15, 63-68. https://doi.org/10.1111/ j.1742-9552.2011.00021.x

Miyake, A., Friedman, N. P., Emerson, M. J., Witzki, A. H., Howerter, A., \& Wager, T. D. (2000). The unity and diversity of executive functions and their contributions to complex "frontal lobe" tasks: A latent variable analysis. Cognitive Psychology, 41, 49-100. https://doi.org/ 10.1006/ cogp.1999.0734

Moniz, M., De Jesus, S. N., Gonçalves, E., Pacheco, A., \& Viseu, J. (2016c). Decision-making in adult unipolar depressed patients and healthy subjects: Significant differences in net score and in non-traditional alternative measures. Neuropsychological Trends, 19, 7-15. https://doi.org/10.7358/neur-2016-019-moni

Moniz, M., De Jesus, S. N., Gonçalves, E., Viseu, J., Baptista, A. S., \& Pacheco, A. (2016d). Computerized Victoria Stroop test in adult unipolar depressed patients and healthy subjects: Influence of age and gender. Psychology, 7, 1-5. https://doi.org/10.4236/psych.2016.71001

Moniz, M., De Jesus, S. N., Gonçalves, E., Viseu, J., Pacheco, A., \& Moreira, S. (2016e). Portuguese version of simple Go/No-Go task: Influence of age in attention and response inhibition reaction time. Psychology, 7, 254-257. https://doi.org/10.4236/psych.2016.72027

Moniz, M., De Jesus, S. N., Pacheco, A., Gonçalves, E., \& Viseu, J. (2016f). Computerized finger tapping task in adult unipolar depressed patients and healthy subjects: Influence of age, gender, education, and hand dominance. Review of European Studies, 8, 1-10. https://doi.org/ 10.5539/res.v8n4p1

Moniz, M., de Jesus, S. N., Pacheco, A., Gonçalves, E., Viseu, J., Brás, M., ... Batista, S. (2017). The influence of planning and response inhibition on cognitive functioning of nonpsychotic unipolar depressed suicide attempters. Europe's Journal of Psychology. 13, 717-732. https://doi.org/10.5964/ejop.v13i4.1385

Moniz, M., De Jesus, S. N., Viseu, J., Gonçalves, E., Moreira, S., \& Pacheco, A. (2016a). Executive dysfunction in nonpsychotic unipolar depressed patients: Assessement by the Wisconsin (Berg) Card Sorting Test. International Journal of Psychological Studies, 8, 112-118. https://doi.org/10.5539/ijps.v8n1p112

Moniz, M., De Jesus, S. N., Viseu, J., Gonçalves, E., Pacheco, A., \& Baptista, A. S. (2016b). Planning dysfunction in nonpsychotic unipolar depressed patients: Assessement by a computerized version of the Tower of London task. International Journal of Psychological Studies, 8, 119-124. https://doi.org/10.5539/ijps.v8n1p119

Moritz, S., Birkner, C., Kloss, M., Jahn, H., Hand, I., Haasen, C., \& Krausz, M. (2002). Executive functioning in obsessive-compulsive disorder, unipolar depression, and schizophrenia. Archives of Clinical Neuropsychology, 17, 477-483. https://doi.org/10.1093/arclin/17.5.477

Mueller, S. T., \& Piper, B. J. (2014). The Psychology Experiment Building Language (PEBL) and PEBL test battery. Journal of Neuroscience Methods, 222, 250-259. https://doi.org/10.1016/j.jneumeth.2013.10.024

Newman, S. D., Greco, J. a, \& Lee, D. (2009). An fMRI study of the Tower of London: A look at problem structure differences. Brain Research, 1286, 123-132. https://doi.org/10.1016/j.brainres.2009.06.031

Piper, B. J., Mueller, S. T., Geerken, A. R., Dixon, K. L., Kroliczak, G., Olsen, R. H. J., \& Miller, J. K. (2015). Reliability and validity of neurobehavioral function on the Psychology Experimental Building Language test battery in young adults. PeerJ, 3, e1460. https://doi.org/ 10.7717/peerj.1460

Roca, M., Vives, M., Lopez-Navarro, E., Garcia-Campayo, J., \& Gili, M. (2015). Cognitive impairments and depression: a critical review. Actas Esp Psiquiatr, 43, 187-193.

Rogers, M. a, Kasai, K., Koji, M., Fukuda, R., Iwanami, A., Nakagome, K., ... Kato, N. (2004). Executive and prefrontal 
dysfunction in unipolar depression: A review of neuropsychological and imaging evidence. Neuroscience Research, 50, 1-11. https://doi.org/10.1016/j.neures.2004.05.003

Rohling, M. L., Green, P., Allen, L. M., \& Iverson, G. L. (2002). Depressive symptoms and neurocognitive test scores in patients passing symptom validity tests. Archives of Clinical Neuropsychology, 17, 205-222. https://doi.org/ 10.1093/arclin/17.3.205

Sheehan, D. V., Lecrubier, Y., Sheehan, K. H., Janavs, J., Weiller, E., Keskiner, A., ... Dunbar, G. C. (1997). The validity of the Mini International Neuropsychiatric Interview (MINI) according to the SCID-P and its reliability. European Psychiatry, 12, 232-241. https://doi.org/10.1016/ S0924-9338(97)83297-X

Sohlberg, M. M., \& Mateer, C. A. (2001). Cognitive Rehabilitation: An Integrative Neuropsychological Approach. New York, NY: The Guilford Press.

Sousa, M. P., Lopes, J. S., \& Vieira, R. (1979). Comparação entre a Escala de Hamilton e o questionário de Beck na quantificacão das depressões. Jornal do Médico, 103, 561-571.
Stordal, K. I., Lundervold, A. J., Egeland, J., Mykletun, A., Asbjørnsen, A., Landrø, N. I., ... Lund, A. (2004). Impairment across executive functions in recurrent major depression. Nordic Journal of Psychiatry, 58, 41-47. https://doi.org/10.1080/08039480310000789

Strauss, E., Sherman, E. M. S., \& Spreen, O. (2006). A Compendium of neuropsychological tests: Administration, norms, and commentary (3rd ed.). Oxford, UK: Oxford University Press.

Swann, A. C., Katz, M. M., Bowden, C. L., Berman, N. G., \& Stokes, P. E. (1999). Psychomotor performance and monoamine function in bipolar and unipolar affective disorders. Biological Psychiatry, 45, 979-988. https://doi.org/10.1016/S0006-3223(98)00172-3

Troyer, A. K., Leach, L., \& Strauss, E. (2006). Aging and response inhibition: Normative data for the Victoria Stroop Test. Aging, Neuropsychology, and Cognition, 13, 20-35.

Wagner, S., Doering, B., Helmreich, I., Lieb, K., \& Tadić, A. (2012). A meta-analysis of executive dysfunctions in unipolar major depressive disorder without psychotic symptoms and their changes during antidepressant treatment. Acta Psychiatrica Scandinavica, 125, 281-292. https://doi.org/10.1111/j.1600-0447.2011.01762.x 